\section{Transvaginal mesh repair of anterior enterocele following radical cystectomy and ileal conduit diversion}

\author{
Jose Daniel Roman \\ Department of Gynaecology, Braemar \\ Hospital, Hamilton, New Zealand
}

\begin{abstract}
Complex pelvic organ prolapses may develop after radical cystectomy. We report a case of an anterior enterocele, which was repaired vaginally and using mesh placed extraperitoneally.

We present the case of a 75-year-old woman who underwent a radical cystectomy and ileal conduit diversion for treatment of invasive bladder cancer. She developed a vaginal vault prolapse 4 months later. She then underwent a vaginal repair and sacrospinous fixation using no mesh. She then presented to our clinic 4 months later with a prolapse recurrence involving an anterior enterocele. She was treated successfully with a transvaginal mesh repair for reconstruction of the anterior vaginal wall, iliococcygeal suspension and colpocliesis. We argue that there is a place for the vaginal use of mesh in the surgical treatment of an anterior enterocele when a substantial loss of endopelvic fascia is encountered. The extraperitoneal technique seems to be a good option while reducing the surgical risks for the patient.
\end{abstract}

\section{Introduction}

Anterior enteroceles are rare and have been reported to count for $1.6 \%$ of all enteroceles. ${ }^{1}$ However, when an anterior vaginal wall resection is performed as part of an anterior exenteration, the incidence of complex vaginal prolapses is higher and it has been estimated as $10 \%{ }^{2}$ or more. Our patient presented with a recurrent anterior enterocele where small bowel loops were deposited behind the pubis. A transvaginal repair was planned and as she had no interest on preserving sexual function, a colpocliesis was also discussed. Due to the extensive loss of the anterior vaginal wall a further repair with native tissue was considered to be inadequate and a mesh repair was discussed with special consideration to postoperative mesh complications.

\section{Case Report}

A 75-year-old woman underwent anterior exenteration and formation of ileal conduit for invasive bladder carcinoma in December 2015. She did develop a vaginal prolapse 4 months later and was referred to a Urogynecologist who performed vaginal vault prolapse repair incorporating arcus support and sacrospinous fixation using no mesh in November 2016. Unfortunately, her vaginal prolapse recurred in April 2017. She was referred to our clinic in July 2017 when we found that she had developed a stage 3 anterior enterocele with superficial vaginal ulceration, a vaginal vault prolapse with a vaginal length of $6 \mathrm{~cm}$, and a stage 2 rectocele. On the other hand, she was taking Prednisone for treating Rheumatoid arthritis. Further vaginal surgery with the use of mesh was discussed with her in extension, with special attention to postoperative mesh complications. She was advised to use local Oestrogen cream beforehand. Her surgery was carried out in August 2017: Repair of anterior enterocele using Gynemesh ${ }^{\circledR}$, iliococcygeal vaginal vault suspension and rectocele repair with colpocliesis. At 10 months follow-up she remains prolapse free.

The surgical procedure was performed under general anaesthesia with endotracheal intubation. On examination in theatre, the vaginal mucosa was found to be ulcerated and with a pinpoint fistula draining peritoneal fluid. A median colpotomy was performed. The ulcerated vaginal skin was dissected off and resected with particular care to preserving the densely adhered peritoneal layer and to avoiding damage to the small bowel loops behind. A sharp release of flimsy adhesions between the small bowel and the peritoneal layer was carried out at the same time. The peritoneal layer, which was densely adhered to the vaginal skin, was then dissected away completely (Figure 1). Two flaps of peritoneal layer were created after the blunt lateral dissection and enlargement of the retropubic space with the purpose of facilitating the overlap of the above layers creating a good support for the extraperitoneal placement of a polypropylene mesh (Gynemesh ${ }^{\circledR}$. Ethicon) that was cut and shaped accordingly. It was then attached to the under-surface of the pubic symphysis using PDS sutures and positioned under no tension. The purposely created proximal mesh arms were attached bilaterally to the iliococcygeal fascia correcting at the same time the vault prolapse. The vaginal mucosa was closed with interrupted sutures of $2 / 0$ vycril. This was followed by a rectocele repair using PDS sutures for the rectovaginal fascia and a per-
Correspondence: Jose Daniel Roman, Department of Gynaecology, Braemar Hospital, 95 Clarence Street, Hamilton, Waikato, New Zealand.

Tel.: 64.7.8397592 - Fax: 64.7.8397522.

E-mail: jdberoman@gmail.com

Acknowledgments: the author would like to thank the staff members of Braemar Hospital Theatre 1 .

Key words: Anterior enterocele; Transvaginal mesh repair; Pelvic organ prolapse.

Conflict of interest: the author declares no potential conflict of interest.

Funding: none

Ethical statement: the author confirms to have obtained written consent from the patient to have her case published.

Received for publication: 9 September 2018. Revision received: 8 October 2018.

Accepted for publication: 21 March 2019

This work is licensed under a Creative Commons Attribution NonCommercial 4.0 License (CC BY-NC 4.0).

(C) Copyright J.D. Roman, 2019

Licensee PAGEPress, Italy

Urogynaecologia 2019; 31:224

doi:10.4081/uij.2019.224

ineal reconstruction using $2 / 0$ vycril. There were no intra or postoperative complications. Local estrogen therapy with Ovestin cream TMMedsafe was started and continued for good after surgery. At 8-month follow-up there was no prolapse recurrence and no mesh erosion. The vaginal length was measured at $5 \mathrm{~cm}$ and the diameter at $1.5 \mathrm{~cm}$.

\section{Discussion and Conclusions}

Long-term studies clearly support radical cystectomy as the most adequate surgical treatment for invasive bladder cancer. ${ }^{3}$ In an effort to increase the patient's quality of life after the above procedure the orthotopic bladder substitution and the ileal conduit (IC) procedure are usually performed afterwards; with an IC frequency of $33 \%$ (22.6-64\%) reported at a 2007 Consensus Conference on Bladder Cancer ${ }^{4}$ and the IC as the most common urinary diversion procedure in the elderly. ${ }^{5}$ Unfortunately, early and late ( $>3$ months) postoperative complications have been described afterwards, including anterior enterocele as the result of 


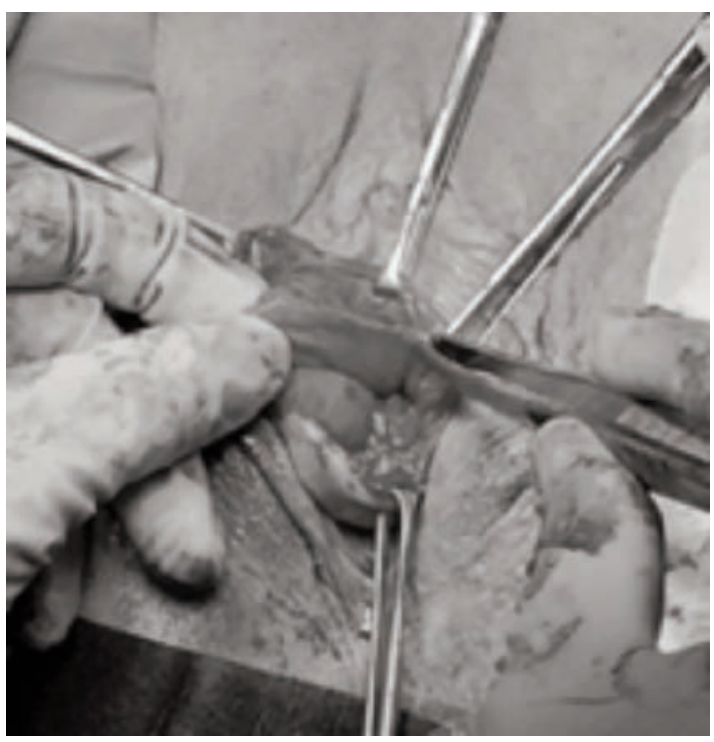

Figure 1. Dissecting the peritoneal layer off the vaginal skin.

the loss of all the anterior and apical support of the vaginal canal.

An abdominal/laparoscopic approach using mesh has been described ${ }^{6}$ for repairing an anterior enterocele but there are still concerns with this approach in view of the distorted anatomy after an exenteration, increasing the risk of intraoperative bowel damage and the development of adhesions or bowel obstruction caused by mesh as it is placed intraperitoneally. On the other hand, the vaginal approach is not free of complications. Colo-vaginal fistulas have been reported with the use of trans-vaginal Vicryl-Prolene mesh $^{7}$ but with no extraperitoneal dissection.
A transvaginal approach using mesh has been reported ${ }^{8}$ using Elevate ${ }^{\mathrm{TM}}$ mesh placed extraperitoneally. Our report confirms the feasibility of a transvaginal approach when using mesh that is positioned extraperitoneally to correct a recurrent anterior enterocele. The use of vaginal mesh should be considered as an option for the surgical treatment of anterior enterocele following radical cystectomy especially when a previous pelvic organ prolapse repair with native tissue has failed. We acknowledge the relative short time of postoperative follow up at 10 months, but we are encouraged to report no early postoperative complications with the above technique.

\section{References}

1. Tukilangas $\mathrm{P}$, Lukban J, Walters $\mathrm{M}$. Anterior enterocele: a report of three cases. Int Urogynecol J Pelvic Floor Dysfunct 2004;15:350-2.

2. Walters M. Post-cystectomy prolapse. In: Howard Goldman, ed. Expert opinions in Female Pelvic medicine and reconstructive surgery. London, UK: JP Medical Ltd; 2013. p 65.

3. Stein JP, Lieskovsky G, Cote R, et al. Radical cystectomy in the treatment of invasive bladder cancer: long-term results in 1,054 patients. J Clinic Oncol 2001;19:666-75.

4. Hautmann RE, Abol-Enein H, Hafez K, et al. Urinary diversion. Urology 2007;69:17-49.

5. Siddiqui KM, Izawa JI. Ileal conduit: standard urinary diversion for elderly patients undergoing radical cystectomy. World J Urol 2016;34:19-24.

6. Abe H. Laparoscopic pelvic organ prolapse repair of a vault prolapse following cystectomy in the female. IUGA Acad 2015;9:141754.

7. Stav K, Dwyer P, Rosamilla A, et al. Transvaginal pelvic organ prolapse repair of anterior enterocele following cystectomy in females. Int Urogynecol J 2009;20:411-5.

8. Graefe F, Beileche K. Vaginal vault prolapse following cystectomy: Transvaginal reconstruction by mesh interposition. Int Urogynecol J 2013;24:1407-9. 